\title{
Effects of method of deployment of artificial units of habitat on microgastropod colonization
}

\author{
M. G. Chapman*, A. J. Underwood, D. Blockley \\ Centre for Research on Ecological Impacts of Coastal Cities, Marine Ecology Laboratories A11, University of Sydney, \\ New South Wales 2006, Australia
}

\begin{abstract}
Artificial units of habitat (AUHs) are used to test theories about structure and configuration of habitat on colonization, effects of disturbances or patterns of biodiversity. They allow control of important components of habitat and where and how habitat is deployed for tests of specific and complex hypotheses. Plastic pot-scourers are widely used for assemblages of small invertebrates because they appear to mimic important characteristics of many biogenic habitats, such as turfing algae or beds of polychaetes. There has, however, been little investigation of the ways in which these AUHs are deployed in the field, although different studies have used different techniques. Here, AUHs were deployed flush with, or raised above the substratum to test hypotheses about rates of colonization by microgastropods according to the method and duration of deployment. In contrast to predictions, duration of deployment did not affect differences between raised and flush AUHs, but, for all periods from 1 to $12 \mathrm{wk}$, flush AUHs consistently acquired larger abundances of those species shared between the two treatments. There were, however, more species unique to the raised than to the flush AUHs. Abundances of common species increased through time from 1 to 12 wk, but this was not due to successional changes in the AUHs deployed for $12 \mathrm{wk}$; the increase was due to a rapid colonization event that occurred during the final period of deployment. Studies on colonization of habitat, whether using AUHs or not, need very careful consideration of experimental design to ensure that results are interpretable.
\end{abstract}

KEY WORDS: Artificial habitat $\cdot$ Colonization $\cdot$ Diversity $\cdot$ Experimental design $\cdot$ Gastropods $\cdot$ Habitat

\section{INTRODUCTION}

The rates at which different species colonize patches of habitat depend on features of the habitat (e.g. McGuinness \& Underwood 1986, Dean \& Connell 1987, Gwyther \& Fairweather 2002), other species already occurring in the patch (e.g. Turchin 1989, Smoothey \& Chapman 2007) and characteristics of the surrounding matrix (e.g. Sousa 1984, Chapman 2002, Russell et al. 2005, Roberts \& Poore 2006). Biological characteristics of the dispersing organisms, including their modes and rates of dispersal (Scheltema 1986, Negrello Filho et al. 2006) and specificity for different types of habitat (Hanski \& Gilpin 1991, Quinn et al. 1994), also determine rates of colonization. Unravelling the many potentially important and confounding factors is difficult unless appropriately designed experi- ments are used to unconfound them. Such experiments have successfully examined colonization of marine fauna into patches of different abiotic or biogenic habitat (e.g. McGuinness \& Underwood 1986, Dean \& Connell 1987, Kelaher 2002, Chapman 2007), but are particularly difficult for some types of habitat. For example, manipulation of the characteristics of turfing algae or other biogenic habitat may not be possible without killing many of the organisms that actually create the patch of habitat, thus destroying its characteristics. Accordingly, for many such tests, artificial units of habitat (AUHs) have been used to overcome some of the logistical problems (Gee \& Warwick 1996, Norderhaug et al. 2002, Kelaher 2003).

Many terrestrial species tend to colonize new patches of habitat by dispersal of one stage of the life cycle. Many plants only colonize by dispersal of seeds, 
either wind-borne or carried by other vectors. Terrestrial vertebrates and many insects typically colonize as adults through active dispersal, although many small invertebrates are also carried passively by the wind, or on other species. Marine organisms typically have more than 1 mode of dispersal. Most aquatic species have propagules that disperse in the water column (Scheltema 1986) over short or very large distances. In addition, many marine invertebrates also disperse as swimming adults, by passive drifting in the water column, or attached to drifting substrata (Aliani \& Molcard 2003). At a local scale, many species can also colonize habitat by moving over the substratum (Cole et al. 2007). Thus, the pathways through which many small marine invertebrates encounter and colonize habitat are diverse and the relative importance of these may vary under different conditions.

AUHs designed to represent patches of habitat can, for example, be placed into different environments, while controlling sizes of patches, distances among patches, etc. (e.g. Virnstein \& Curran 1986, Olabarria 2002, Chapman 2007). They can be designed to have different characteristics of habitat-structure (Kelaher 2003, Atilla et al. 2005), or can be deployed in multiple sites and with different surrounding matrices (Cole et al. 2007), thus controlling not only the features of patches of habitat of interest, but also the surroundings through which dispersing animals must move. Deploying AUHs at set times also allows some control over any influence that an existing assemblage has on colonization by other taxa (Chapman 2007) and guarantees experimental patches are all of the same age.

Plastic pot-scourers have been shown in numerous studies to be colonized by a diverse assemblage of intertidal or subtidal organisms. They have been used successfully to test hypotheses about rates and timing of successional change (Underwood \& Chapman 2006), scales of spatial variation in assemblages (Chapman \& Underwood 2008), colonization of common versus rare species (Chapman \& Underwood 2008), effects of environmental disturbances (Hall et al. 2000) and as a standardized habitat for broad-scale assessments of marine biodiversity (Gee \& Warwick 1996). Chapman \& Underwood (2008) showed that pot-scourers deployed on subtidal reefs on the coast of New South Wales, Australia were colonized by a diverse suite of small gastropods, some of which appeared to have colonized as adult micro-gastropods and some of which were recruits of larger species.

New recruits can only colonize AUHs via the watercolumn, whereas adults can colonize via the water column or by crawling across surrounding substratum (Levin 1984, Wilson 1994). If each of these modes of colonization occur, AUHs that are in contact with the substratum should be colonized by a different suite of animals, or at a different rate from AUHs that are held above the substratum and, thus, only accessible via the water column. All AUHs may be colonized by species that move through the water, whereas only AUHs on the substratum should be accessible to organisms crawling over the substratum. Species in the water column may encounter and colonize AUHs faster than those moving over the substratum because they can disperse over larger distances and are therefore more likely to find patches of new habitat. Some studies use AUHs deployed on racks above the substratum (Rule \& Smith 2007), whereas others deploy them in contact with the substratum (Underwood \& Chapman 2006), but there has been no comparison of the species that colonize AUHs deployed in these different ways. Finding generalized conclusions about colonization of marine invertebrates to AUHs may be problematic if a very different suite of species colonize habitats deployed in different ways.

This study compared colonization of AUHs (plastic pot-scourers) deployed in contact with the rocky substratum or held above the substratum, but in the same depth of water for 1, 4 or $12 \mathrm{wk}$. When analysing temporal changes in development of assemblages, it is crucial to separate the period of development from the actual time when processes are occurring (Underwood \& Chapman 2006). Any comparison of an assemblage that has developed over $P$ months with one that has developed over a shorter period $(p)$ is intrinsically confounded because if the 2 sets of habitat were initiated at the same time at the start of the experiment, the $P$ includes a time $(P-p)$ where habitats deployed over the longer period can be subjected to events that did not occur during $p$. Thus, any difference between assemblages that develop during period $P$ as opposed to $p$, may be due to the longer time that habitat is available for colonization, or to particular events occurring in the $(P-p)$ period not sampled by the 'shorter-term' habitats. These events have nothing to do with the length of time that habitat is available. One can attempt to control for this by deploying habitat for shorter periods within the early and late parts of the longer period (discussed in detail in Underwood \& Chapman 2006).

Therefore, 2 different 1 - and 4 -wk periods were incorporated into the experiment to attempt to separate effects of the length of deployment from the specific period that the AUHs were deployed. Although the AUHs were colonized by a wide range of taxa, only gastropods were analysed here because they are relatively quick and easy to identify, are very diverse, and disperse as larvae through the water column or as adults by crawling, swimming, or drifting. Specific hypotheses tested were: (1) species and abundances of gastropods colonizing AUHs raised above the substratum should differ from those colonizing AUHs on the substratum and these 
differences should increase the longer the AUHs are deployed; (2) over longer periods, more species should colonize AUHs on the substratum compared to raised AUHs because crawling species will encounter the former, but not raised AUHs; (3) over short periods, the numbers of species may be similar between suspended AUHs and those deployed on the substratum (if early colonization is primarily via the water column), or there should be more species in AUHs on the substratum (if colonization over the substratum is rapid).

\section{MATERIALS AND METHODS}

Experimental design. AUHs were deployed as shown in Table 1. Three sets were deployed at the start and removed after 1, 4 or 12 wk. A 4 th set was deployed $1 \mathrm{wk}$ prior to the removal of the 4 -wk set to provide information about colonization during the later portion of that period of deployment. A 5th set was similarly deployed from Weeks 8 to 12 , to provide information about colonization during a 2nd 4-wk period within the longer period of $12 \mathrm{wk}$. Although these do not cover all time periods (which was logistically too difficult), AUHs deployed for either the 4- or 12-wk period can be compared to 2 sets of AUHs deployed for shorter periods within the 4 or $12 \mathrm{wk}$. These 2 sets were deployed towards the start and towards the end of the longer period of deployment.

Methods. This experiment was done in 2 randomly chosen sites, approximately $100 \mathrm{~m}$ apart, on rocky reef in approximately 2 to $4 \mathrm{~m}$ depth of water at Long Bay, Australia (as described in Chapman \& Underwood 2008). At each site, 25 AUHs were attached flush with the rock surface and 25 were attached to vertical posts, approximately $20 \mathrm{~cm}$ high. There was approximately $20 \mathrm{~cm}$ between adjacent AUHs. The posts were bolted to rocky substratum in deeper water but adjacent to the areas with the flush AUHs, which ensured that all AUHs were at the same depth in the water, but the raised ones were not lying on the natural substratum. As far as possible, treatments were interspersed. Each AUH (plastic pot-scourer) was attached to a seperate

Table 1. Details of the experimental design: date of deployment (D) and collection (C) of 5 sets (D1 to D5) of artificial units of habitat (AUH). Dates are day/month in 1999

\begin{tabular}{|c|c|c|c|c|c|c|}
\hline & $20 / 7$ & $27 / 7$ & $10 / 8$ & $17 / 8$ & $14 / 9$ & $12 / 10$ \\
\hline D1 & D---- & ----C & & & & \\
\hline D2 & D-.-- & --.--.. & ---N- & $---C$ & & \\
\hline D3 & D---- & -------. & 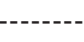 & ------ & 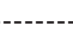 & -----C \\
\hline D4 & & & D---- & $---C$ & & \\
\hline D5 & & & & & D-... & -----C \\
\hline
\end{tabular}

piece of plastic foam and then onto a base of fibre cement sheeting (each approximately $12 \times 12 \mathrm{~cm}$ ). These bases were then attached to the post or rock surface. Thus, the raised AUHs were not simply suspended in the water column, but each sat on a separate base, in a similar manner to the flush AUHs, but not on the natural substratum. It was extremely unlikely that microgastropods could colonize these AUHs by climbing up the posts and around the rear surfaces of the backing boards. AUHs were sampled after the different periods of deployment (Table 1$) ; \mathrm{n}=5$.

The AUHs were retrieved by coring into the foam backing plate to form a seal, which prevented organisms escaping when the AUHs were collected. The back surface of the foam backing plate was brushed clear of any organisms and then the entire sample was immediately transferred to an individual plastic bag.

The entire unit was preserved in $7 \%$ formalin-seawater before being rinsed with freshwater over a $500 \mu \mathrm{m}$ sieve, unrolled and rinsed again. The animals then sorted under a dissecting microscope. When the number of gastropods was very large, samples were sub-sampled by volume using a plankton splitter and the numbers adjusted accordingly. All gastropods were identified to the greatest possible taxonomic resolution, either species or morphospecies (i.e. consistently but not formally identified).

\section{RESULTS}

\section{Patterns in the assemblages}

To compare assemblages among AUHs, each site was analysed separately using PERMANOVA (Anderson 2001) of Bray-Curtis dissimilarities calculated from untransformed data (Treatment, 2 levels, raised or flush; Deployment, 5 levels, see Table 1). Sites were analysed separately because of the difficulty of interpreting complex interactions in multivariate data. There was a significant interaction between Treatment and Deployment in each site (Site 1: $F_{4,40}=2.17, \mathrm{p}<0.001$; Site 2: $\left.F_{4,40}=2.93, \mathrm{p}<0.001\right)$. Post-hoc pairwise tests showed that, for 7 of the 10 comparisons, the assemblage in raised AUHs was significantly different from that in flush AUHs; exceptions were D1, D3 and D4 (deployed for 1, 12 and $1 \mathrm{wk}$, respectively; Table 1) in Site 1.

This pattern was supported by Bray-Curtis dissimilarities among replicate AUHs within either and between the 2 treatments (Table 2) and the nMDS plots (illustrated for Site 1 in Fig. 1). For all deployments in Site 2 and for D2, D4 and D5 in Site 1, the mean dissimilarity between treatments was greater than the dissimilarity within each treatment (Table 2). Similarly, for each deployment, the assemblages from 
Table 2. Average Bray-Curtis \% dissimilarities for the assemblage of gastropods among replicate artificial units of habitat (AUH) within raised (R) or flush (F) AUHs and between the raised $(\mathrm{R})$ and flush $(\mathrm{F})$ treatments for each deployment; $\mathrm{n}=5$

\begin{tabular}{|c|c|c|c|c|c|c|}
\hline \multirow[t]{2}{*}{ Deployment } & \multicolumn{3}{|c|}{ Site $1 \_$} & \multicolumn{3}{|c|}{ Site 2} \\
\hline & $\mathrm{R}$ & $\mathrm{F}$ & R vs. F & $\mathrm{R}$ & $\mathrm{F}$ & R vs. F \\
\hline D1 & 79 & 56 & 74 & 72 & 44 & 82 \\
\hline D2 & 60 & 55 & 68 & 47 & 51 & 59 \\
\hline D3 & 73 & 52 & 70 & 54 & 51 & 64 \\
\hline D4 & 63 & 66 & 69 & 51 & 57 & 64 \\
\hline D5 & 29 & 33 & 51 & 31 & 37 & 44 \\
\hline
\end{tabular}

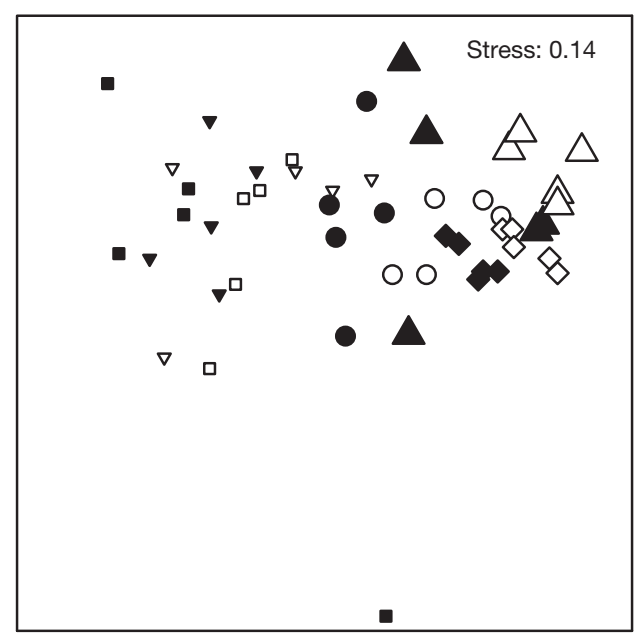

Fig. 1. nMDS ordination of the gastropod assemblages that colonized artificial units of habitat (AUH) raised above (filled symbols) or flush with (empty symbols) the substratum in Site 1; deployments as in Table 1: D1 $=\mathbf{\square} ; \mathrm{D} 2=\mathbf{\bullet} ; \mathrm{D} 3=\boldsymbol{\Delta} ; \mathrm{D} 4=\mathbf{\nabla}$;

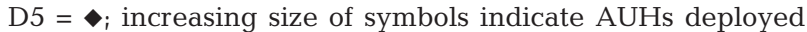
for 1,4 or $12 \mathrm{wk}$

the raised and flushed treatments were plotted separately in nMDS ordinations, although there was overlap between raised and flushed treatments from one deployment to another. The lack of significant difference in D1 (Site 1) was mainly due to one outlier of the raised treatment (Fig. 1), which caused a very large within-treatment dissimilarity for this set (Table 2). Despite the lack of a significant difference among treatments for D3 at Site 1, the assemblages plotted separately, but there was again much greater variation among AUHs in the raised than in the flush AUHs, creating non-significant differences between treatments. Nevertheless, the plots indicate that assemblages developed over 12 wk (D3; Site 1 in Fig. 1) in flush AUHs were more different from those in AUHs deployed for shorter periods, whereas, for the raised AUHs, the differences between the 12-wk and younger assemblages were smaller.
Despite differences in assemblages between the raised or flush AUHs and some significant differences among the periods of deployment, there was a general trend in the development of the assemblages. Both 1-wk deployments (D1 and D4), although different, plotted on the left of the ordination, with the 4- and 12-wk deployments towards the right (Fig. 1). Assemblages were much more similar in AUHs deployed for 4 or 12 wk than either assemblage was to those in AUHs that had only been deployed for $1 \mathrm{wk}$. Post-hoc pairwise tests also showed that for flush AUHs in Site 1, assemblages were similar in D1 and D4 (each deployed for $1 \mathrm{wk}$ ) and that those in AUHs deployed for 4 or 12 wk differed significantly $(p<0.05)$ from those in any set deployed for only $1 \mathrm{wk}$. Raised AUHs had fewer significant differences, specifically D1 = D2 = D4 and D3 = D5. This indicated that some event during the last $4 \mathrm{wk}$ of the experiment may have caused these latter 2 assemblages to become more similar.

The 2 sites showed very similar changes through time for each treatment (shown for the raised AUHs in Fig. 2).

Sixty-two species/morphospecies of gastropods were identified, although only 12 were responsible for $75 \%$ of the dissimilarities between raised and flush AUHs (5 to 9 species for each deployment and site separately). These 12 species were: Amphithalamus incidatus (13 to $36 \%$ of the total dissimilarity between raised and flush AUHs for different deployments/sites), A. pyramis (3 to $9 \%$ ), Zafra atkinsoni (1 to $18 \%$ ), Rissoella micra (2 to $15 \%$ ), Rissoella confusa robertsoni (1 to $22 \%$ ), juvenile Austrocochlea porcata (0 to $5 \%$ ),

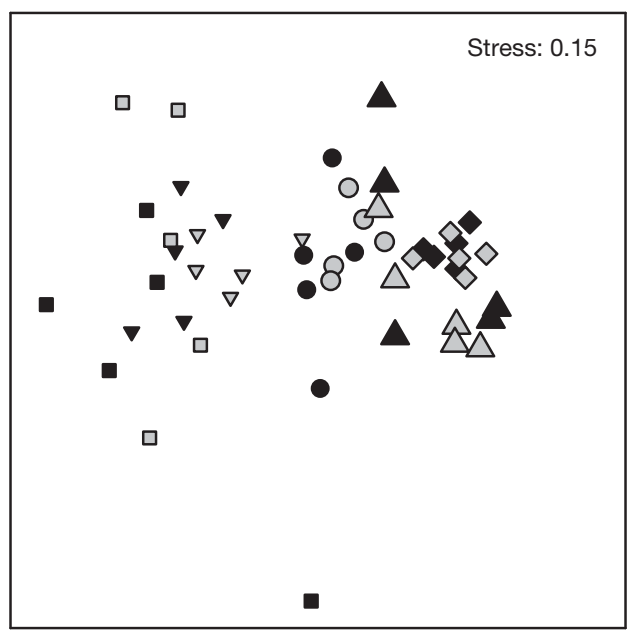

Fig. 2. nMDS ordination of the gastropod assemblages that colonized AUHs raised above the substratum in Site 1 (black symbols) and Site 2 (grey symbols); deployments as in Table 1: D1 $=\mathbf{\square} ; \mathrm{D} 2=\boldsymbol{\bullet}$; D3 = $\mathbf{\Delta} ; \mathrm{D} 4=\boldsymbol{\nabla} ; \mathrm{D} 5=\boldsymbol{\bullet}$ increasing size of symbols indicate AUHs deployed for 1,4 or $12 \mathrm{wk}$ 
Eatoniella atropurpurea (0 to 8\%), E. galbinia (2 to $10 \%)$, Crassitoniella flammea (1 to $13 \%)$, Cantharidella picturata (0 to $8 \%$ ), Pisinna albizona (0 to $8 \%$ ), Mitrella sp. A (4 to $17 \%$ ) and Tricolia variablilis (3 to $12 \%$ ).

\section{Numbers of species and abundances of individual species}

Numbers of species and abundances of individual species were analysed using analyses of variance (full details of design in Table 3). SNK tests were used for comparisons of means. Where appropriate, data were pooled (Underwood 1997). The mean number of species varied significantly between treatment and deployment, with similar patterns in each site (Table 3). Averaged across sites, there were more species per flush $\mathrm{AUH}$ than per raised $\mathrm{AUH}$, although differences were not significant for D4 or D5 (Fig. 3).

For raised AUHs, there were significantly more species in those deployed for 4 wk towards the end of the experiment (D5) than for any other deployment, which did not differ significantly. For flush AUHs, there were no significant differences among periods of deployment. For flush and raised AUHs, the mean number of species per AUH increased (although not significantly) between Weeks 1 and 4 (D1-D2, D4-D5), but, by
Week 12, mean numbers had remained more or less constant, or had, in fact, decreased slightly. Although there were more species towards the end of the experiment than the beginning (D1 vs. D4, D2 vs. D5) in most treatment/site combinations, overall patterns remained consistent.

The total number of species per treatment reflected mean number per AUH (Fig. 3), particularly in Site 2, where there were more species in flush AUHs than in raised AUHs for all deployments other than D5. This contradicted the prediction that more species would colonize flush AUHs than raised AUHs the longer the AUHs were deployed.

Because it was thought that with longer deployment, more species would colonize flush AUHs than raised AUHs, it was predicted that there would be an increase in the number of species unique to flush AUHs with longer deployment. There was, however, no consistent temporal pattern in the occurrences of shared species or those unique to either treatment. Therefore, the data from each deployment were combined to examine the frequencies with which different species colonized raised or flush AUHs. Of the 62 species, 41 were common to flush and raised AUHs, being found in 2-94 of the 100 deployed AUHs. Thirteen species were only found in raised AUHs and 8 only in flush AUHs; these numbers do not differ from random colonization by species to the 2 types of scourers $\chi^{2}=$

Table 3. ANOVA of mean number of species per AUH for number of species and individual species of gastropods; Treatment (fixed), Deployment (fixed), Site (random); $\mathrm{n}=5_{i}{ }^{*} \mathrm{p}<0.05_{;}{ }^{* *} \mathrm{p}<0.01_{i}{ }^{* * *} \mathrm{p}<0.001$

\begin{tabular}{|c|c|c|c|c|c|c|c|c|c|}
\hline \multirow[t]{2}{*}{ Source } & \multirow[t]{2}{*}{$\mathrm{df}$} & \multicolumn{2}{|c|}{ Number of species } & \multicolumn{2}{|c|}{ Amphithalamus incidatus } & \multicolumn{2}{|c|}{ Mitrella sp. A } & \multicolumn{2}{|c|}{ Tricolia variablilis } \\
\hline & & MS & $F$ & MS & $\mathrm{F}$ & MS & $F$ & MS & $F$ \\
\hline Treatment $=\mathrm{T}$ & 1 & 82.8 & $331.24^{*}$ & 28572 & ${ }^{\mathrm{b}} 40.27^{* * *}$ & 1394 & ${ }^{b} 11.37^{* *}$ & 749 & 8.91 \\
\hline Deployment = D & 4 & 121.5 & $11.34^{*}$ & 18383 & ${ }^{\mathrm{b}} 25.91^{* * *}$ & 977 & ${ }^{b} 7.97^{* * *}$ & 181 & ${ }^{\mathrm{c}} 5.20^{* * *}$ \\
\hline Site $=\mathrm{S}$ & 1 & 39.7 & ${ }^{\mathrm{a}} 4.46^{*}$ & 13 & b0.02 & 472 & b3.85 & 10 & ${ }^{\mathrm{c}} 0.30$ \\
\hline $\mathrm{T} \times \mathrm{D}$ & 4 & 26.6 & a $2.99^{*}$ & 6723 & ${ }^{\mathrm{b}} 9.48^{* *}$ & 294 & ${ }^{\mathrm{b}} 2.41$ & 57 & ${ }^{\mathrm{c}} 1.64$ \\
\hline $\mathrm{T} \times \mathrm{S}$ & 1 & 0.3 & ${ }^{\mathrm{a}} 0.03$ & 97 & 0.12 & 2 & 0.02 & 84 & ${ }^{c} 2.41$ \\
\hline $\mathrm{D} \times \mathrm{S}$ & 4 & 10.7 & ${ }^{\mathrm{a}} 1.20$ & 135 & 0.17 & 13 & 0.1 & 32 & 0.87 \\
\hline $\mathrm{T} \times \mathrm{D} \times \mathrm{S}$ & 4 & 6.1 & 0.67 & 82 & 0.11 & 85 & 0.65 & 11 & 0.29 \\
\hline Residual & 80 & 9 & & 777 & & 131 & & 36 & \\
\hline \multirow[t]{2}{*}{ Source } & \multirow[t]{2}{*}{$\mathrm{df}$} & \multicolumn{2}{|c|}{ Eatoniella galbinia } & \multicolumn{2}{|c|}{ Rissoella micra } & \multicolumn{2}{|c|}{ Rissoella confusa robertsoni } & \multicolumn{2}{|c|}{ Zafra atkinsoni } \\
\hline & & MS & $F$ & MS & $F$ & MS & $F$ & MS & $F$ \\
\hline Treatment $=\mathrm{T}$ & 1 & 537 & 4.63 & 162 & ${ }^{\mathrm{b}} 0.59$ & 300 & ${ }^{\mathrm{b}} 0.47$ & 1739 & 3.63 \\
\hline Deployment = D & 4 & 125 & 5.83 & 8811 & ${ }^{\mathrm{b}} 31.89^{* * *}$ & 43626 & b $68.86^{* * *}$ & 1442 & 2.92 \\
\hline Site $=\mathrm{S}$ & 1 & 129 & $5.75^{*}$ & 1291 & ${ }^{\mathrm{b}} 4.67^{*}$ & 1394 & ${ }^{\mathrm{b}} 2.20$ & 350 & 2.35 \\
\hline $\mathrm{T} \times \mathrm{D}$ & 4 & 39 & 0.42 & 1149 & ${ }^{b} 4.16^{* *}$ & 402 & ${ }^{\mathrm{b}} 0.63$ & 658 & 0.8 \\
\hline $\mathrm{T} \times \mathrm{S}$ & 1 & 116 & $5.16^{*}$ & 3 & 0.01 & 167 & 0.25 & 480 & 3.22 \\
\hline $\mathrm{D} \times \mathrm{S}$ & 4 & 21 & 0.96 & 341 & 1.19 & 407 & 0.6 & 494 & 3.328 \\
\hline $\mathrm{T} \times \mathrm{D} \times \mathrm{S}$ & 4 & 94 & $4.18^{* *}$ & 65 & 0.23 & 179 & 0.27 & 820 & $5.51^{* * *}$ \\
\hline Residual & 80 & 22 & & 287 & & 673 & & 149 & \\
\hline
\end{tabular}



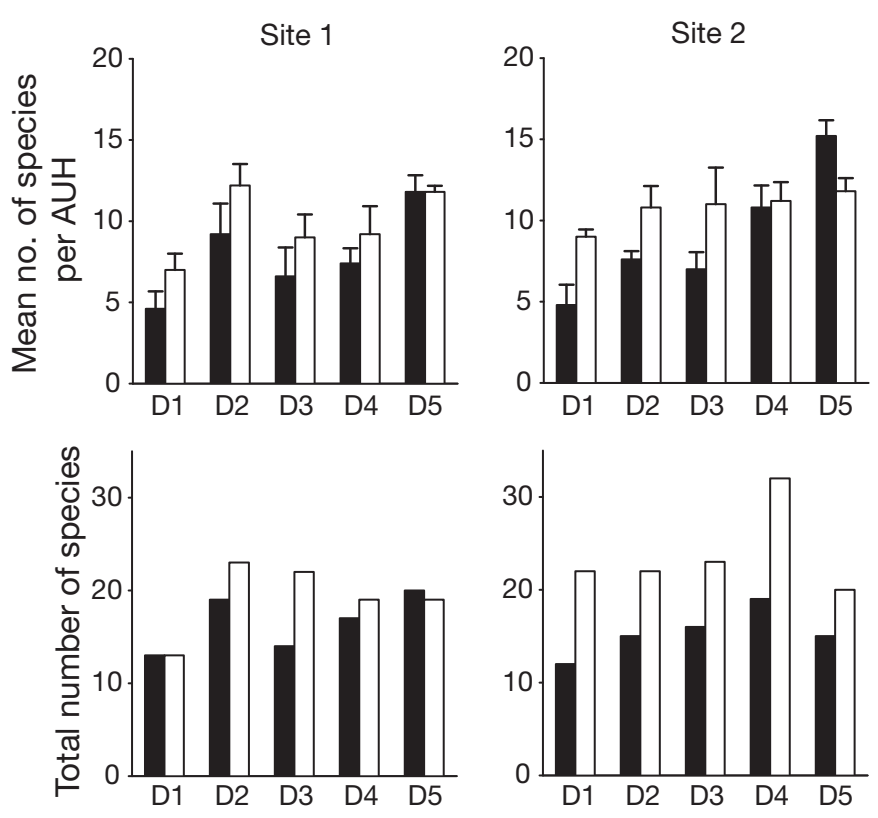

Fig. 3. Mean (+ $\mathrm{SE} ; \mathrm{n}=5$ ) and total number of species in raised (black bars) or flush (empty bars) AUHs in each site for each of the 5 deployments (D1 to 5 ; see Table 1)

$1.19,1 \mathrm{df}, \mathrm{p}>0.05)$. The 21 species that were unique to either of the treatments were found in between 1 (14 species) and 4 (1 species) AUHs.

To match the occurrences of unique species in $\leq 4$ AUHs, the 41 shared species were therefore subdivided into those found in $>4$ AUHs (considered common) or in $\leq 4$ (considered rare). Of the 22 species found in $>4$ AUHs, 16 were found in more flush AUHs than raised AUHs and only 4 showed the opposite pattern $\left(\chi^{2}=7.21,1 \mathrm{df}, \mathrm{p}<0.01 ; 2\right.$ were found in the same number of raised or flush AUHs). Of the 19 shared species that were relatively rare (i.e. found in 2 to 4 AUHs), 5 were found in more of the flush AUHs and only 1 was found in more of the raised AUHs (the other 13 were found in equal numbers of raised or flush AUHs).

Most species were too sparse to reliably analyse and interpret differences in densities. Therefore, to examine patterns for individual species, densities of the 5 species that were found in the largest numbers of AUHs (70 to 94 AUHs; Amphithalamus incidatus, Mitrella sp. A, Tricolia variabilis, Eatoniella galbinia and Rissoella micra) and the 5 species with largest overall abundances (1408 to 4105 individuals; $A$. incidatus, $R$. micra, $R$. confusa robertsoni, Zafra atkinsoni and Mitrella sp. A) were analysed across treatments, deployments and sites using analyses of variance. Because the snails were very patchily distributed among AUHs, the analyses were done using raw data and separately with data transformed to $x^{0.25}$, which served to downweight effects of very large abundances in individual AUHs. Results of the different analyses were relatively consistent, only differing with respect to minor details of complex interactions. Therefore, although some variances were heterogeneous, analyses of untransformed data are presented in order to keep the scale of measurement similar across species. These analyses are relatively robust to heterogeneous variances when there are many independent estimates of variance (as was the case here) (Underwood 1997).

Five of the 7 species showed significant effects of treatment, although in 4 of these, Treatment interacted with Deployment, or with Deployment and Site (Table 3). For Eatoniella galbinia and Zafra atkinsoni, which showed significant interactions with Site, differences were in the same direction, the interaction caused by whether or not differences were significant. Therefore data for all species were pooled across sites to illustrate general patterns (Fig. 4). For all short deployments (i.e. $1 \mathrm{wk}, \mathrm{D} 1$ and D4, or $4 \mathrm{wk}, \mathrm{D} 2$ and D5), there were more snails of each species in flush AUHs than in raised AUHs (Fig. 4), although differences were not all significant. After $12 \mathrm{wk}$, the pattern was reversed in three of the species, significantly so for Rissoella micra.

With respect to period and timing of deployment, patterns differed between raised and flush AUHs for some species. Although densities of Tricolia variabilis were smaller in both treatments deployed for only $1 \mathrm{wk}$, differences among treatments were not statistically significant. Despite differences in mean number of Mitrella sp. A between raised AUHs and flush AUHs (apparently varying with Deployment), Mitrella sp. A and Rissoella c. robertsoni showed no significant interaction with Treatment. Mitrella sp. A had larger densities in D5 (the 2nd 4-wk deployment) and $R$. c. robertsoni showed D5 > D3 > D1 = D2 = D4 (SNK tests). Patterns were similar in the 2 treatments for Amphithalamus incidatus (D3 > D5 > others, which were all similar), but differences were only significant for the flush AUHs. R. micra similarly showed greatest densities in D3 and D5, but, in raised AUHs, D3 had significantly more snails than D5; for flush AUHs, the opposite pattern was true. The analyses of Eatoniella galbinia and $Z$. atkinsoni gave complex interactions with sites, but in all cases the patterns were similar, although differences were of different magnitudes. $E$. galbinia had largest densities in D5, which was also true for $Z$. atkinsoni in flush AUHs.

In general, therefore, despite complex interactions, all species generally had larger abundances in flush AUHs and, with respect to deployment, D3 and D5 tended to have the largest densities. This indicates that 

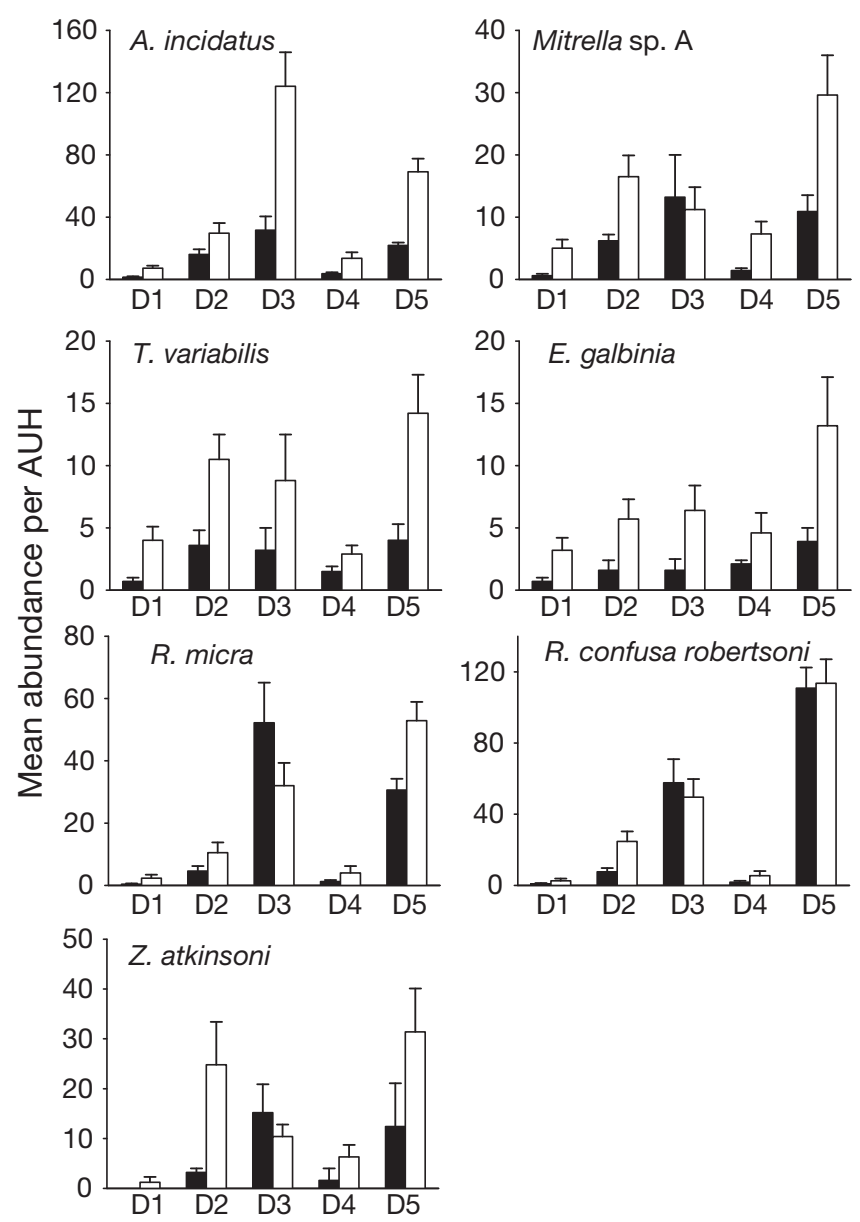

Fig. 4. Mean $(+\mathrm{SE} ; \mathrm{n}=10)$ abundance per $\mathrm{AUH}$ of the most abundant and widespread species in raised (black bars) or flush (empty bars) AUHs for each of the 5 deployments (D1 to D5); data averaged across sites. See Table 1 for dates of deployment; Table 3 for taxonomic names in full

the large numbers of snails found in AUHs deployed for $12 \mathrm{wk}$, may not be due to the length of time that the AUHs were deployed, but due to increased rates of colonization during the last $4 \mathrm{wk}$ of deployment.

\section{DISCUSSION}

Deployment of the AUHs on or above the substratum had a large effect on the abundances and diversity of species of gastropods that colonized them. Those raised off the substratum generally had fewer species per unit, smaller abundances of common species and fewer of the rare species. In both treatments, the AUHs were placed on a base and sampled in the same way, by isolating the AUH and the small area of base, thus preventing loss of individuals into the surrounding water while the AUHs were being collected
(Underwood \& Chapman 2006). Thus, differences between raised and flush AUHs are best explained by the proximity of the substratum. Experiments that have isolated the two main pathways of colonization to AUHs (Cole et al. 2007) or other small patches of habitat (Negrello Filho et al. 2006) have shown that different species colonize new patches of habitat either through the water column, over the substratum, or both, although neither of those studies specifically examined gastropods.

Yet, there has previously been no quantitative comparison between the ways that pot-scourers are deployed in the field when being used as patches of habitat to study patterns of colonization, diversity, etc. Thus, some researchers have consistently deployed them on the substratum (e.g. Gee \& Warwick 1996, Underwood \& Chapman 2006), whereas others have deployed them on racks raised above the substratum (e.g. Atilla \& Fleeger 2000, Rule \& Smith 2007). It is clear that, for tests of any hypotheses about diversity and/or abundances of specific taxa, the method of deployment may change the patterns observed, especially if the distance between the substratum and the $\mathrm{AUH}$ is not consistent among treatments or sites. Although the hypotheses here were only tested for gastropods, previous research has shown that patterns of colonization of AUHs by small gastropods closely follow those of other components of the assemblage (authors' unpubl. data), so these results may have much wider applicability.

Despite the differences we found, raised AUHs still accumulated many species. Most species were found in both raised and flush AUHs, suggesting that much of the colonization was through the water column. These included very common and rare species. Because the gastropods were all $>500 \mu \mathrm{m}$ in length and many were found in AUHs that had only been deployed for $1 \mathrm{wk}$, these must have colonized as drifting adults, although recruitment may have increased the abundances in the AUHs deployed for 4 or $12 \mathrm{wk}$. The larger abundances in flush AUHs deployed on the substratum might mean that the animals also colonize by crawling over the substratum, or that the water layer closest to the substratum carried more snails than higher up in the water column. Although many small gastropods have been observed to move through the water column on mucus threads (Newell 1962, Gosselin \& Chia 1995), they may also move across the surface of the substratum by saltation if disturbed from surrounding habitat.

The flush AUHs were not placed in direct contact with biogenic habitat that was likely to contain large numbers of these animals (e.g. algal turfs; Kelaher 2003), but on bare rock or crusts, and the AUHs were on a thin backing board. Similar (and many of the 
same) species have shown similar colonization of artificial habitat on rocky shores when it was deployed at some distance and separated from coralline turf by bare rock (Olabarria 2002). Thus, these animals are very mobile as adults and readily exploit newly available habitat.

In contrast, there were slightly more species unique to raised AUHs than to flush AUHs. These were all extremely rare, many were singletons, or found only in $1 \mathrm{AUH}$, which may reflect greater dispersal of rare species through the water column.

The length of deployment was not a major factor in the development of the assemblage, at least between 4 and $12 \mathrm{wk}$. Both deployments of $1 \mathrm{wk}$ were colonized by only relatively few individuals and species, but between 4 and $12 \mathrm{wk}$, patterns were more complex. Although there was no great effect on numbers of species, abundances were much larger during the second deployment of $4 \mathrm{wk}$ than during the first. Because this second deployment was only 8 wk after the first, it is unlikely to reflect major seasonal patterns, but probably local environmental conditions (see also Underwood \& Chapman 2006).

The large amount of colonization into D5 caused reinterpretation of the pattern found in AUHs deployed for $12 \mathrm{wk}$. Typical methods of examining processes such as succession provide habitat at a starting time and then examine changes in that habitat over time (e.g. Sousa 1979, Benedetti-Cecchi \& Cinelli 1996). Changes in abundances, assemblages, etc. over time are thought to result from the development of the assemblage in the patch of habitat and environmental conditions. In this case, the greater abundances in D3 (deployed at the same time as D1 and D2, but for longer) indicated that deployment for $12 \mathrm{wk}$ increases colonization compared to deployment for only $4 \mathrm{wk}$. The comparison with D5 (deployed for $4 \mathrm{wk}$ during the end of the deployment of D3) showed, however, that length of deployment did not cause larger numbers of animals in D3, but that some event during the last $4 \mathrm{wk}$ of deployment increased colonization across all habitats. As described by Underwood \& Chapman (2006), great care needs to be taken with designing experiments about colonization of habitat through time to prevent poor interpretation of the results.

Overall, deploying AUHs in flush versus raised configurations caused development of different assemblages, so future studies must take this into account. More species were found only in raised than only in flush AUHs, but species found in both configurations were generally more abundant in flush AUHs than raised AUHs. The former is presumably some as-yetunknown consequence of the general conclusion that most colonization by small gastropods is via the water column, rather than movement across the substratum.
Acknowledgements. The Australian Research Council through its Special Research Centre Scheme and the University of Sydney supported this research. We thank numerous research support staff for their assistance in the field, laboratory and in front of a computer. A. Palmer and R. Murphy and 3 anonymous referees provided helpful comments on an earlier draft of this manuscript. The work described in this paper and the production and authorship of the paper, conform in every respect to the University of Sydney's Policies on Ethical and Responsible Behaviour in Research.

\section{LITERATURE CITED}

Aliani S, Molcard A (2003) Hitch-hiking on floating marine debris: macrobenthic species in the Western Mediterranean Sea. Hydrobiologia 503:59-67

Anderson MJ (2001) A new method for non-parametric multivariate analysis of variance. Austral Ecol 26:32-46

Atilla N, Fleeger JW (2000) Meiofaunal colonization of artificial substrates in an estuarine embayment. PSZN I: Mar Ecol 21:69-83

Atilla N, Fleeger JW, Finelli CM (2005) Effects of habitat complexity and hydrodynamics on the abundance and diversity of small invertebrates colonizing artificial substrates. J Mar Res 63:1151-1172

> Benedetti-Cecchi L, Cinelli F (1996) Patterns of disturbance and recovery in littoral rock pools: nonhierarchical competition and spatial variability in secondary succession. Mar Ecol Prog Ser 135:145-161

Chapman MG (2002) Early colonization of shallow subtidal boulders in two habitats. J Exp Mar Biol Ecol 275:95-116

Chapman MG (2007) Colonization of novel habitat: tests of generality of patterns in a diverse invertebrate assemblage. J Exp Mar Biol Ecol 348:97-110

Chapman MG, Underwood AJ (2008) Scales of variation of gastropods densities over multiple spatial scales: comparison of common and rare species. Mar Ecol Prog Ser $354: 147-160$

Cole VJ, Chapman MG, Underwood AJ (2007) Landscapes and life-histories influence colonization of polychaetes to intertidal biogenic habitats. J Exp Mar Biol Ecol 348:191-199

Dean RL, Connell JH (1987) Marine invertebrates in an algal succession. III. Mechanisms linking habitat complexity with diversity. J Exp Mar Biol Ecol 109:249-273

Gee JM, Warwick RM (1996) A study of global biodiversity patterns in the marine motile fauna of hard substrata. J Mar Biol Assoc UK 76:177-184

Gosselin LA, Chia FS (1995) Distribution and dispersal of early juvenile snails: effectiveness of intertidal microhabitats as refuges and food sources. Mar Ecol Prog Ser 128: 213-223

Gwyther J, Fairweather PG (2002) Colonisation by epibionts and meiofauna of real and mimic pneumatophores in a cool temperate mangrove habitat. Mar Ecol Prog Ser 229: 137-149

Hall SJ, Gray SA, Hammett ZL (2000) Biodiversity-productivity relations: an experimental evaluation of mechanisms. Oecologia 122:545-555

Hanski I, Gilpin M (1991) Metapopulation dynamics: brief history and conceptual domain. Biol J Linn Soc 42:3-16

Kelaher BP (2002) Influence of physical characteristics of coralline turf on associated macrofaunal assemblages. Mar Ecol Prog Ser 232:141-148

Kelaher BP (2003) Effects of frond length on diverse gastropod assemblages in coralline turf. J Mar Biol Assoc UK 83: 159-163 
Levin LA (1984) Life history and dispersal patterns in a dense infaunal polychaete assemblage: community structure and response to disturbance. Ecology 65: $1185-1200$

McGuinness KA, Underwood AJ (1986) Habitat structure and the nature of communities on intertidal boulders. J Exp Mar Biol Ecol 104:97-123

Negrello Filho OA, Underwood AJ, Chapman MG (2006) Recolonization of infauna on a tidal flat: an experimental analysis of modes of dispersal. J Exp Mar Biol Ecol 328: $240-250$

Newell R (1962) Behavioural aspects of the ecology of Peringia (= Hydrobia) ulvae (Pennant) (Gastropoda, Prosobranchia). Proc Zool Soc Lond 138:49-75

Norderhaug KM, Christie H, Rinde E (2002) Colonisation of kelp imitations by epiphyte and holdfast fauna: a study of mobility patterns. Mar Biol 141:965-973

Olabarria C (2002) Role of colonization in spatio-temporal patchiness of microgastropods in coralline turf habitat. J Exp Mar Biol Ecol 274:121-140

Quinn RM, Lawton JH, Eversham BC, Wood SN (1994) The biogeography of scarce vascular plants in Britain with respect to habitat preference, dispersal ability and reproductive biology. Biol Conserv 70:149-157

Roberts DA, Poore AGB (2006) Habitat configuration affects colonisation of epifauna in a marine algal bed. Biol Conserv 127:18-26

Rule MJ, Smith SDA (2007) Depth-associated patterns in the development of benthic assemblages on artificial substrata deployed on shallow, subtropical reefs. J Exp Mar Biol Ecol 345:38-51

Editorial responsibility: Roger Hughes, Bangor, UK
Russell BD, Gillanders BM, Connell SD (2005) Proximity and size of neighbouring habitat affects invertebrate diversity. Mar Ecol Prog Ser 296:31-38

Scheltema RS (1986) On dispersal and planktonic larvae of benthic invertebrates: an eclectic overview and summary of problems. Bull Mar Sci 39:290-322

> Smoothey AF, Chapman MG (2007) Small-scale variability in the dispersion of the sea urchin Heliocidaris erythrogramma among boulders. Mar Ecol Prog Ser 340:89-99

Sousa WP (1979) Experimental investigations of disturbance and ecological succession in a rocky intertidal algal community. Ecol Monogr 49:227-254

Sousa WP (1984) Intertidal mosaics: patch size, propagule availability, and spatially variable patterns of succession. Ecology 65:1918-1935

Turchin P (1989) Population consequences of aggregative movement. J Anim Ecol 58:75-100

Underwood AJ (1997) Experiments in ecology. Their logical design and interpretation using analysis of variance. Cambridge University Press, Cambridge

Underwood AJ, Chapman MG (2006) Early development of subtidal macrofaunal assemblages: relationships to period and timing of colonization. J Exp Mar Biol Ecol 330:221-233

Virnstein RW, Curran MC (1986) Colonization of artificial seagrass versus time and distance from source. Mar Ecol Prog Ser 29:279-288

Wilson WH (1994) Dispersal of soft-sediment benthos: migration through the water-column or through the sediment? In: Wilson WH, Stricker SA, Shinn GL (eds) Reproduction and development of marine invertebrates. Johns Hopkins University Press, Baltimore, MD, p 302-312

Submitted: April 10, 2008; Accepted: May 28, 2008

Proofs received from author(s): August 20, 2008 